\title{
Learner Autonomy and the English Language Independent Learning Center in Mainland China
}

\author{
ZHANG Xi \\ School of Foreign Languages \\ Wuhan University of Technology \\ Wuhan, China \\ xizhang@whut.edu.cn
}

\begin{abstract}
With the development of Internet technology and further research on English as Second Language (ESL) teaching pedagogy, in recent years there has been a rapid expansion of the English language Independent Learning Center over Mainland China. Based on the theory of learner autonomy by Schwienhorst, this paper attempts to explore the positive impact the Independent Learning Center has on English learning for nonEnglish major college students, to discuss the challenges and potential problems it brings about, and to propose possible strategies accordingly. Undoubtedly, this new mode of learning will continue to promote an authentic and autonomous English learning environment for ESL students in China, playing an important role in improving learners' speaking and listening skills.
\end{abstract}

Keywords-Independent Learning Center; learner autonomy; English learning; Chinese students

\section{INTRODUCTION OF INDEPENDENT LEARNING CENTER IN MAINLAND CHINA}

The Independent Learning Center (ILC), or self-access center, is a relatively new concept that appeared with development of technology and further research on foreign language teaching pedagogy. It sprang up first in western countries in 1980s, then in the colleges and universities in Southeast Asia area including Hong Kong and Macau in 1990s[1]. In mainland China, since the National Ministry of Education announced the "Requirements on Course of College English Teaching”, and proposed a both computer-based and classroom-based multimedia teaching mode in 2004, over 180 universities in China carried out teaching experimental reforms and set up independent learning centers, which is aligned with the pedagogical mode of autonomous learning [2]. Besides, as Hua stated in his paper, in recent years, due to the rapid rise of the number of university students and the relatively insufficiency of course teachers, combined with varied needs of both individual and society, it is urgent for universities to cultivate an independent learning ability among students. And the swift development of high technology, especially the wide spreading of the computer tech and Internet has offered a favorable condition for the foundation of the ILCs [1].

Therefore, the purpose of ILC is to provide a fixed computer-based English learning site, "designed to accommodate learners of different levels, styles, goals and interests" [3], assisting the users to cultivate and enhance their independent learning ability. The ILC offers a wide range of resources including language-learning materials, multimedia computers with access to e-mail and the Internet, TV/VCRs, and CD and audio cassette players for listening and pronunciation practice. In the universities in Mainland China, ILC built for College English course is usually composed of one controlling center and digital language labs, facilitated with phonic and audio equipment and computers, and English learning software and other materials.

For instance, in Wuhan University, one of the main pilot projects of national English ILC construction and a representative of ILC in Mainland China, the computer labs are distributed in four different regions on campus with centralized administration, equipped with more than 1000 computers. With an ID card, each student could log in at any lab center to learn English in online system at free time after class, and their activities are monitored by the managing computer set at the controlling room in the center. Entering university as a freshman, the students are informed by their college English teachers that over the following four semesters they are required to complete an online software course called "New Era Interactive English" that mainly develop learners' listening and speaking skills. When they log into the software, they watch segments of videos of American campus life and social conversations, then they imitate the speeches of some characters, play roles in the video conversations, answer questions orally, do listening comprehension exercises, and learn the usages of vocabulary and idioms with related practice. The students get immediate feedback and hints of answers after they finish the exercises. At the end of every unit each student's performance is manifested through a histogram, and there is a test at the end of every level as well. Students are encouraged to self-study every week and their progress and grades are monitored by their teachers over the semester and will account for part of their final grade of the course.

\section{LEARNER AUTONOMY AND ILC}

Students' learning process in the ILCs in Mainland China is obviously a manifestation of learner autonomy. Defined by Schwienhorst, learner autonomy is not simply self-dependent learning, but a learner-centered approach to learning that learners have the capacity to constantly work to achieve a goal 
under the guidance and supervision of teachers [4]. Learners make their own decisions, but also have responsibility for themselves.

Schwienhorst views learner autonomy as a "learnercentered approach to learning, where learners are encouraged to critically reflect on their learning process and develop a personally meaningful relation to it"[4]. It is the capacity to effectively take charge of one's own learning process. Furthermore, three essential approaches are mentioned in the development of learner autonomy: "reflection and awareness (the intentional learner); interaction and collaboration (the communicator); and experimentation and active collaboration (the experimenter or researcher)” [4].

In the first approach learners' responsibility in their own learning process includes the development of critical reflection and linguistic self-awareness for language learning. So language learners are not only trying to express themselves in a new language environment, but also develop an awareness of the new culture with various tools of audio, video and photography. During the learning process learners reflect on the way they learn the language and the related strategies they use and they will be more aware of their own strengths and weaknesses in language learning.

Interaction and collaboration are also important factors in learner autonomy. Undoubtedly, an interactive learning environment plays an important role in the second language learning; in the process of interaction and communication the way learners explore to carry out a conversation and the corrective feedback they get offer them opportunities to modify and develop their output in the new language. Learning a language is essentially learning to use a language to express and communicate, thus the meaningful interaction is obviously significant.

Through experimentation and exploration, learners could find out the most effective ways for themselves in language learning with the help of user-friendly tools and authentic materials, such as "large databases of authentic materials and search tools to find personally relevant material” [4]. Besides, "a pedagogical framework that brings these materials and tools within reach of their autonomy" is needed to realize a personal connection between language learners and the language [4].

However, given the mainstream mode of language education in Mainland China, which is quite close to the "spoon-feeding" form, learners have lost much of their autonomy. Many of them are very passive learners, sitting quietly in the class and waiting for their teachers to instill in them the knowledge of the language. The consequence of this education mode is that Chinese students are far better at reading and writing than speaking and listening, which is actually a big problem for them with the background of globalization and the widespread use of English.

Under such circumstances, the set up of ILC provided Chinese English learners with a really good opportunity to develop their learner autonomy as well as acquire English proficiency.

In the ILC of Wuhan University, during the process of imitation and role-playing in video conversations with the native characters, students are actually interacting with these native speakers and producing target-like language to accomplish the task. What is special about this software is that it has the ability of speech recognition and comparison so that the learner have to imitate the accent and intonation of the native speakers in the video to meet the requirement of each task, otherwise he has to do the role playing task again and again until he meets the requirement, and then he can proceed to the next task. So in this process, the learner has clear awareness of how he performs in the English speaking and the distance of his speech and pronunciation with that of native speakers. Moreover, the histogram of their performance at the end of each unit and level also helps learners to reflect and take charge of their learning progress and the improvements they could make in the future. With the software they become intentional learners with the ability of reflection and awareness, and actively participate and explore in the activities. Thus the three main approaches of learner autonomy by Schwienhorst are met in this process, in which students need to learn independently, set up their goals, and take charge of their learning process and progress, while teachers play a role of guide and supervision.

\section{AdVAnTAges}

The set up of ILC in universities in Mainland China creates a "culture of autonomous learning" on campus, which compensates the insufficient language practice in English classroom [1]. Similar with the situation in Taiwan, as indicated by Hsu, Chinese students are accustomed to receiving knowledge passively from teachers' lectures, and normally non-English major students only have three to four hours every week in class to study English [3]. So the limited time and lecture-centered teaching style makes it challenging for the students to efficiently learn and practice English. ILC offers students a chance to make most of the time after class to take responsibility in their learning, keep track of the progress, and turn the comprehensible input into meaningful, purposeful and motivational output.

Moreover, students are exposed in an authentic language context provided by the software. As what is stated above, students could rarely have many chances to practice English in class or outside the class in such a non-native environment, so most students have difficulty using English communicating with people, especially with speaking problems. Wallis argued that the offering of self-access facilities is "one way to allow learners access to extra exposure to and practice in the target language" and "that they act as a bridge to the real world in that they may lead learners to use English in other unstructured situations outside the learning environments"[5]. The segments of video are all daily conversations on campus and social occasions in the US, full of colloquial expressions and phrases, which could be hardly found in formal textbooks taught in classrooms. Besides, the speaking exercise highlights the practice of English phonetic skills like liaison, stress and intonation, which are very vital in colloquial communication, though not the main targets in College English class for nonEnglish major students. Once a student could make full use of these language materials and take initiative in learning, he/she 
would definitely make progress in English proficiency, and skills like speaking, listening, vocabulary and pragmatics.

In addition, the online-based software integrates rich multimedia resources and tools for the learners. Not only pictures, videos, vocal recordings are provided, the software also contains useful tools like hint buttons for every exercise, and an auditory dictionary. The combination of all these elements makes the independent learning process a big contrast with teacher-centered classroom learning, which seems more boring to the learners. The interaction nature of the learning process infuses learners with more motivation and interest to explore and progress gradually.

Finally, students could get prompt feedback as soon as they finish each task, and their learning rate of progress is also under supervision of their teachers chronically. For example, for the role-play task, the feedback of their pronunciation is immediately given by indicating to the student whether he has to do it again. Through the online system, teachers could check each student's task progress, their grades, and their learning durations for each unit. So the teachers could regularly remind those students who don't complete the online course regularly, help students with individual problems and give them advice.

\section{Challenges And Potential PRoblems}

As an experimental project in Chinese universities, SIL still faces some challenges and many problems have already popped up.

Many students don't have much conscious and capacity of learner autonomy and haven't found their own ways arranging their schedule well at the centers. Hsu pointed out "development of learner autonomy is influenced by their cultural and educational backgrounds and teacher attitudes. However, students who are used to a certain teaching and learning styles may find it difficult to change their learning habits, may resist independent learning” [3]. So it can be both emotionally and intellectually challenging for Chinese student to work autonomously. The survey carried on in the self-access center by Hsu also shows that individual learners have different study habits and would develop differing degrees of independence [3]. As a result, many students cannot adapt themselves to the flexible mode of independent learning and manage their time at the centers where the Internet is accessible, which is the biggest problem lab managers' face. A large amount of students are found playing computer games, watching movies, or chatting online for hours; some students cheat by asking their friends to do the exercises for them, copying others' answers, or installing some "speeding software" to complete the tasks; some put one-sided emphasis on speed rather than quality of learning, which is especially conspicuous at the end of semester when many students are trying to cram for the final grade; some of them are unfamiliar with the overall goal or the functional design of the system, while lacking interest and motivation for English learning, which undermines the efficiency of dependent learning. Generally, the amount of time every individual spent on learning varies greatly, and so does the effect of learning on students of different levels.
Due to the high cost of hardware device, there is insufficiency of equipment to meet the needs of learners. According to Chen's statistics, only when the rate of student number and computer number reaches 12:1, could ILC satisfy the needs of students to study the course online for two to three hours per week. Right now even in some pilot projects with better condition, this rate is only 17:1 [2]. Without the funding from the government, many colleges have difficulty to raise such a great amount of money to set up an ILC, not to mention the problems with the maintenance and support for the device. For example, only on the purchase of hardware device Wuhan University invested $¥ 2,000,000$ (about \$ 300, 000).

Also, there is a lack of skillful technical staff and professional tutoring teachers in the ILC. In many ILCs there are only several office workers who are only responsible for daily routine, such as locking the door and preventing the loss of property, but no professional technical staff or teachers. Even with the staff and teachers, the lack of training on internet-based software and proper pedagogy make them unable to offer students suitable approaches or strategies in autonomous learning.

\section{SOLUTIONS AND STRATEGIES}

In helping students develop their learner autonomy ability and better manage their time, each ILC should adopt some measures to help learners to be self-disciplinary, and English teachers should provide support as well. Related rules and disciplines are indispensible but not enough; ILC could install some monitoring software and give some penalty to the students who play for more than one hour, for example, screenlocking. Besides, both teachers and students should have the right consciousness about their roles. The teacher is a guide, monitor, evaluator and counselor who should advocate the idea of learner autonomy to the students at the beginning of the semester, and help students realize their roles as a real master in their learning. Hsu provided a very good suggestion for this, which to some degree is also a solution to deal with the lack of professional tutoring teachers in ILC- -It may be crucial for English teachers to take turns as facilitators, advisors or counselors on duty in the SAC. They would be required to give help and advice to learners how to identify and effectively exploit the materials in the center, to guide them to set goals for improving their learning, to discuss with them about their problems they encounter, to suggest activities for them, and to assist them to become more interested and responsible for their own learning" [3]. In this way the students could be assisted and the center doesn't need to employ extra professional tutors. What's more, students' learning outcome would be effectively enhanced if teachers further strengthen the management and supervision of students' learning progress. For instance, it would be a good way to report students' progress to the class at least once per month to remind them to timely schedule their learning plans.

For the high expense of hardware device and the insufficient equipment, nowadays more and more students have installed the learning software on their personal computers under the instructions of technical staff in their universities so that they don't need to all cram into the computer lab to do the 
learning task. In this way it will be more convenient for students to learn at any time in any place with Internet access.

Finally, ILC should try to employ sufficient technical staff, and at the same time a managing system should be further implemented and professional training should be carried out at intervals, so that students could have prompt technical assistance and supervision in need, and the device could be well maintained [6]. The staff could also know more about students' opinions and problems in the learning through survey and questionnaire, and the data could be collected as the reference for center adjusting and improvements.

\section{CONCLUSION}

Though ILC in mainland China still face many potential problems stated above, its rapid developments have already created an authentic and autonomous English learning environment for English as Second Language (ESL) learners in China and played an important role in promoting learners' speaking and listening skills. So with the further construction and management of ILC, along with more guidance from teachers to help students get into the right track of autonomous learning, the pedagogical target of College English course could be more effectively achieved with integrated language skills cultivated in learners.

\section{REFERENCES}

[1] W. Hua, "The research report about setting up the self-access language learning center," (In Chinese) in Foreign Language World, vol. 6, pp. 43-48, 2003.

[2] X. Chen, "About the construction and management of English selfaccess learning center," (In Chinese) in Foreign Language Teaching and Research, vol. 54, pp. 110-111, 2010.

[3] S. Hsu, "Independent learning at a self-access center", Academic Seminar in the National Kaohsiung Marine University's $83^{\text {rd }}$ Founding Anniversary, pp. 126-138, 2007, unpublished.

[4] K. Schwienhorst, Learner Autonomy and CALL Environments, $1^{\text {st }}$ ed., London: Routledge, 2007.

[5] R. Wallis, "Independent learning: what do students at our centre do and why do they do it?", Supporting Independent English Language Learning in the 21st Century: Proceedings of the Independent Learning Association Conference Inaugural, pp. 1-15, 2005.

[6] W. Hua, "Self-access language learning center-a new type of language learning environment," (In Chinese) in Foreign Language World, vol. 5, pp. 41-45, 2001. 